\title{
Body weight in rats: Effects of day vs. night meals
}

\author{
FRED P. VALLE and ROY NIKAIDO \\ University of British Columbia, Vancouver, British Columbia, Canada V6T IW5
}

\begin{abstract}
Laboratory rats were fed for $2 \mathrm{~h}$ during the day or night. These single-meal-fed rats initially lost weight but subsequently gained weight at the same rate as ad-lib-fed control animals. Time of meal had no effect on body weight. Single-meal feeding does not lead to obesity in rats.
\end{abstract}

Rats on time-restricted feeding schedules (e.g., access to food for $2 \mathrm{~h}$ a day) adapt to the demands of consuming, digesting, and storing large amounts of food over short periods of time in a variety of ways, both behavioral and physiological. These adaptations include a decrease in the latency of eating when food is made available (e.g., Ghent, 1951), an increase in the amount eaten in any given meal (e.g., Baker, 1955), as much as a $50 \%$ increase in the size of the stomach resulting in greater load capacity (Holečková \& Fábry, 1959), and changes in many of the metabolic pathways in adipose and liver tissue, resulting in an enhancement of lipogenesis (Fábry \& Braun, 1967; Leveille, 1970). The efficacy of the latter physiological adaptations is shown by the fact that, relative to freely fed control animals, percent weight of meal-fed rats is higher than percent food intake, i.e., meal-fed rats use food more efficiently.

There is some disagreement, however, as to just how successful these adaptations are. A study by Hollifield and Parson (1962) reported that rats fed for $2 \mathrm{~h}$ a day gained more weight than rats with free access to food. This unexpected finding has appeared in at least one paperback health book, Nutrition Against Disease (Williams, 1973), in which it is used to justify the proscription that people on diets should avoid single large daily meals since, "Experiments with rats, which are by nature nibblers, have shown conclusively that if they are forced to abandon their nibbling behavior by being given access to food only two hours per day (one meal a day) they become obese'" (p. 106).

Attempts to replicate the Hollifield and Parson experiment have not reproduced their results, although there are inconsistencies among the results of the replications (Leveille \& Hanson, 1965; Muiruri \& Leveille, 1970; Stevenson, Feleki, Szlavko, \& Beaton, 1964). A problem that arises when one attempts to reconcile these diverse findings is that in

This research was supported by a Careers 75 grant to Roy Nikaido from the Government of the Province of British Columbia. Requests for reprints should be sent to Fred P. Valle, Department of Psychology, University of British Columbia, Vancouver, British Columbia, Canada V6T 1W5. none of the studies cited is it reported (1) what time of day the meal-fed rats were fed relative to the day/night cycle or (2) what time of day the rats in the various groups were weighed. The latter variable could produce some differences in results, since meal-fed rats will obviously weigh more following the meal than before it. The former variable could be of importance, since rats normally eat close to $70 \%$ of their daily intake during the night portion of the day/night cycle (Siegel \& Stuckey, 1947) and it has been suggested that conditions for fat synthesis exists only at night in ad-lib-fed rats (LeMagnen, Devos, Gaudillière, Louis-Sylvestre, \& Tallon, 1973). Thus, it is possible that rats transferred from ad-lib feeding to a single meal fed at night might more easily adjust to the new schedule than rats switched to a single meal fed during the day. It may be, then, that some of the discrepancies among the results of studies dealing with the effects of meal feeding on rats could be due to unreported differences in feeding times (relative to day/night cycles) or weighing times (relative to feeding times).

The present study investigated these possibilities by meal-feeding one group of rats for $2 \mathrm{~h}$ during the day (Group AM) and a second group for $2 \mathrm{~h}$ during the night (Group PM). Both of these groups were weighed just before and just after their daily meals, i.e., at their daily minimum and maximum weights. A third group of rats with free access to food (Group Ad Lib) was weighed once during the day and once during the night.

\section{METHOD}

The subjects were 30 male Wistar rats, approximately 75 days old, from Woodlyn Laboratories Ltd., Guelph, Ontario. Upon receipt, the animals were housed in single cages and allowed to habituate to the laboratory, to the diet used, and to handling/ weighing procedures for 14 days. The rats were then ranked by weight and assigned to one of three groups on the basis of those ranks so that three groups of equal average weight were obtained.

The diet used was a mixture of $500 \mathrm{~g}$ ground Purina Lab Chow and $200 \mathrm{ml}$ Mazola corn oil. The rats were maintained on a 12-h day/night cycle, with light onset occurring at $0700 \mathrm{~h}$. Group AM was fed from 1000 to $1200 \mathrm{~h}$ and Group PM was fed from 2200 to $2400 \mathrm{~h}$. Every second day, food intake and body weight were measured. The ad-lib control animals were weighed at 1200 and $2400 \mathrm{~h}$ on those days, and their food intake was measured at 
$2400 \mathrm{~h}$. Water was available to all subjects at all times. Temperature in the laboratory was maintained at approximately $23^{\circ} \mathrm{C}$.

During the course of the experiment, one subject from the control group had to be destroyed because of "whirling disease" and one subject from Group PM had to be discarded because of an experimental error. In order to maintain an equal number of subjects in all groups, one subject from Group AM, chosen at random, was discarded at the end of the experiment. The loss of these subjects did not bias the matched weights of the three groups: average predeprivation weights for the animals that completed the experiment were $339.4,340.6$, and $340.6 \mathrm{~g}$ for Groups AM, PM, and Ad Lib, respectively.

\section{RESULTS}

\section{Body Weights}

Figure 1 presents mean body weights for the three groups of rats over the 36 days of the experiment by blocks of 6 days. Both pre- and postmeal weights are shown for the two meal-fed groups; only one curve, average daily weight, is shown for the control animals since there was virtually no difference in weight in these animals between the 1200- and 2400-h weighings (average difference, $-0.3 \mathrm{~g}$ ). It can be seen that there was no effect of day vs. night meals on meal-fed rats and that meal-fed rats always weighed less than control animals: $88 \%$ of control weight before meals, $92 \%$ following meals. Hence, under no condition in the present experiment did meal-fed rats gain more weight than "nibblers"; rather, following an initial period of adjustment to the feeding schedule characterized by a decrease in weight, meal-fed rats gained weight at virtually the same rate as ad-lib-fed rats.

\section{Food Consumption}

Average (mean of daily medians) food intake over the course of the experiment was $16.4 \mathrm{~g}$ for Group AM,

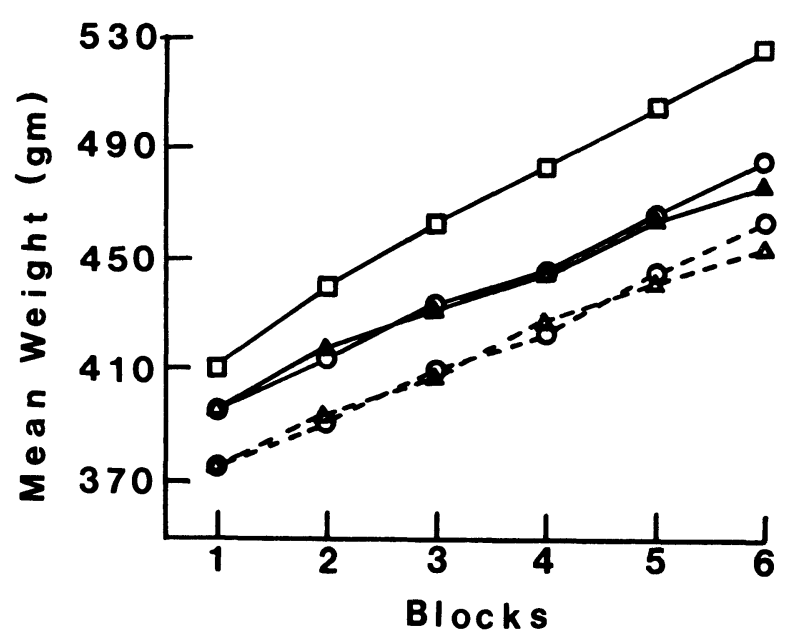

Figure 1. Mean body weight over blocks of 6 days for ad-libfed control animals (squares), animals fed for $2 \mathrm{~h}$ during the day (circles), and animals fed for $2 \mathrm{~h}$ during the night (triangles). Solid lines for the meal-fed subjects indicate postmeal weights, broken lines, premeal weights.
16.6 $\mathrm{g}$ for Group PM, and $20.2 \mathrm{~g}$ for Group Ad Lib. Hence the AM and PM animals ate approximately $82 \%$ as much as the control animals. The fact that relative weight was greater than relative food intake is due, as noted earlier, to the more efficient use of food by meal-fed rats.

\section{DISCUSSION}

The results of the present study show that rats switched from ad-lib feeding to meal feeding adapt equally well to day or night meals. The results also show, however, that no matter when they are fed or weighed, meal-fed rats do not become obese relative to control animals.

Given these results, it is clear that Hollifield and Parson's (1962) atypical data could not have resulted from the time of day they fed or weighed their animals. It has been noted (Stevenson et al., 1964) that Hollifield and Parson's control animals gained less weight over the course of their experiment than is usual for the strain. In light of that fact and in light of the results of the present experiment (which are consistent with those reported by Leveille \& Hanson, 1965, and Muiruri \& Leveille, 1970), the most appropriate conclusions would appear to be that (i) after an initial adaptation period characterized by weight loss, single-meal-fed rats gain weight at the same rate as normal ad-lib control animals, and (ii) Hollifield and Parson's finding of greater weight gain by meal-fed animals was due to idiosyncracies of their five control subjects.

Therefore, contrary to the claim made in Nutrition Against Disease (Williams, 1973), there is no "conclusive" evidence that rats become obese when forced to abandon their nibbling behavior. Rather, there is conclusive evidence that, under a variety of conditions, single-meal-fed rats gain weight at the same rate as ad-lib nibblers, a feat that points to a remarkable degree of behavioral and physiological flexibility in an opportunistic feeder.

\section{REFERENCES}

BAKER, R. A. The effects of repeated deprivation experience on feeding behavior. Journal of Comparative and Physiological Psychology, 1955, 48, 37-42.

FÁBRY, P., \& BRAUN, T. Adaptation to the pattern of food intake: Some mechanisms and consequences. Proceedings of the Nutrition Society, 1967, 26, 144-152.

Ghent, L. The relation of experience to the development of hunger. Canadian Journal of Psychology, 1951, 5, 172-176.

HoleČKovA, F., \& FÁBRY, P. Hyperphagia and gastric hypertrophy in rats adapted to intermittent starvation. British Journal of Nutrition, 1959, 13, 260-266.

Hollifield, G., \& Parson, W. Metabolic adaptations to a "stuff and starve" feeding program. II. Obesity and the persistence of adaptive changes in adipose tissue and liver occurring in 
rats limited to a short daily feeding period. Journal of Clinical Investigations, 1962, 41, 250-253.

LeMagnen, J., Devos, M., Gaudillière, J. P., LouisSylvestre, J., \& Tallon, S. Role of a lipostatic mechanism in regulation by feeding of energy balance in rats. Journal of Comparative and Physiological Psychology, 1973, 84, 1-23.

LeVeille, G. A. Adipose tissue metabolism: Influence of periodicity of eating and diet composition. Federation Proceedings, 1970, 29, 1294-1301.

LeVeille, G. A., \& Hanson, R. W. Influence of periodicity of eating on adipose tissue metabolism in the rat. Canadian Journal of Physiology and Pharmacology, 1965, 43, 857-868.

MuiruRI, K. L., \& LeVeille, G. A. Metabolic adaptations in meal-fed rats: Effects of increased meal frequency or ad libitum feeding in rats previously adapted to a single daily meal. Journal of Nutrition, 1970, 100, 450-460.

Siegel, P. S., \& STUCKey, H. L. The diurnal course of water and food intake in the normal mature rat. Journal of Comparative and Physiological Psychology, 1947, 40, 271-274.

Stevenson, J. A., Feleki, F. V., Szlavko, A., \& Beaton, J. R. Food restriction and lipogenesis in the rat. Proceedings of the Society for Experimental Biology and Medicine, 1964, 116, 178-182.

Williams, R. J. Nutrition against disease. New York: Bantom, 1973.

(Received for publication June 24, 1976; revision accepted August 19, 1976.) 